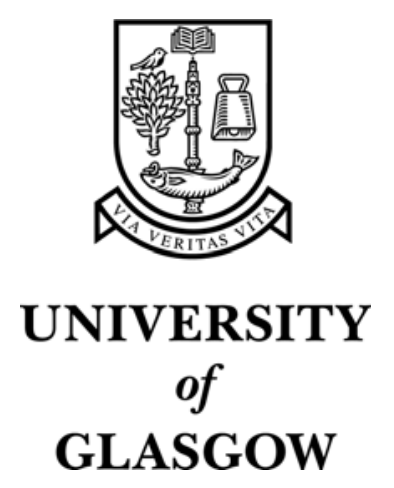

MacLeod, J. and Davey Smith, G. and Metcalfe, C. and Hart, C. (2005) Is subjective social status a more important determinant of health than objective social status? Evidence from a prospective observational study of Scottish men. Social Science and Medicine 61(9):pp. 1916-1929.

http://eprints.gla.ac.uk/3140/ 
Is subjective social status a more important determinant of health than objective social status? Evidence from a prospective observational study of Scottish men.

John Macleod ${ }^{1}$, George Davey Smith², Chris Metcalfe ${ }^{2}$, Carole Hart ${ }^{3}$

${ }^{1}$ Department of Primary Care and General Practice, Primary Care Clinical Sciences and Learning Centre Building, University of Birmingham, Edgbaston, Birmingham B15 2TT.

${ }^{2}$ Department of Social Medicine, Canynge Hall, University of Bristol, Whiteladies Road, Bristol, BS8 2PR.

3 Public Health and Health Policy, Division of Community Based Sciences, University of Glasgow, 1 Lilybank Gardens, Glasgow, G12 8RZ

Correspondence to John Macleod: telephone 44 (0)121 414 3351; fax 44 (0)121 414 3759; j.a.macleod@bham.ac.uk

Word counts, Abstract: 363, Main paper including tables and references: 9055 


\title{
Is subjective social status a more important determinant of health than objective social status? Evidence from a prospective observational study of Scottish men.
}

\begin{abstract}
Both subjective and objective measures of lower social position have been shown to be associated with poorer health. A psychosocial, as opposed to material, aetiology of health inequalities predicts that subjective social status should be a stronger determinant of health than objective social position. Few studies have empirically examined this question and those that have are predominantly cross-sectional. In a workplace based prospective study of 5232 Scottish men recruited in the early 1970s and followed up for 25 years we examined the association between objective and subjective indices of social position, perceived psychological stress, cardiovascular disease risk factors and subsequent health. Lower social position, whether indexed by more objective or more subjective measures, was consistently associated with an adverse profile of established disease risk factors. Perceived stress showed the opposite association. The main subjective social position measure available was based on individual perceptions of workplace status (as well as their actual occupation, men were asked whether they saw themselves as “employees”, “foremen” or "managers”). Compared to foremen, employees had a small and imprecisely estimated increased risk of all cause mortality (age adjusted hazard ratio $1.11(0.96,1.30)$ ), whereas managers had a more marked decreased risk (age adjusted hazard ratio 0.75 (0.62, 0.90)). The strongest predictors of increased mortality were father's manual as opposed to non-manual occupation (fully adjusted hazard ratio 1.16 (1.03-1.31)); lack of car access (fully adjusted hazard ratio 1.12 (1.02-1.23)) and shorter stature, (an
\end{abstract}


indicator of material deprivation in childhood, fully adjusted hazard ratio 1.09 (1.021.16) per $10 \mathrm{~cm}$ decrease). In the fully adjusted analyses, perceived work-place status was only weakly associated with mortality (hazard ratio for employees compared to foremen $1.09(0.93,1.27)$, managers compared to foremen $0.91(0.74,1.10))$. In this population it appears that objective material circumstances, particularly in early life, are a more important determinant of health than perceptions of relative status. Conversely, higher perceived stress was not associated with poorer health, presumably because, in this population, higher stress was not associated with material disadvantage. Together these findings suggest that, rather than targeting perceptions of disadvantage and associated negative emotions, interventions to reduce health inequalities should aim to reduce objective material disadvantage, particularly that experienced in early life.

Key words: Health inequality, psychosocial factors, subjective social status, social position, mortality, morbidity. 


\section{Is subjective social status a more important determinant of health than objective social status? Evidence from a prospective observational study of Scottish men.}

\section{Background}

Social position and health

For much of the $20^{\text {th }}$ Century, and especially over the past 25 years, epidemiological research has focused on the relation between social position and health (Davey Smith, 1997). In one sense, this relation appears straightforward. Poorer health is associated with social disadvantage. In the UK at least, this has been true for most overall health indicators since the $19^{\text {th }}$ century (Chadwick, 1842) (Engels, 1845) (Stevenson, 1923) (Logan, 1954) (Hart, 1972) (Black, Morris, Smith \& Townsend, 1980) (Davey Smith, Carroll, Rankin \& Rowan 1992) (Davey Smith, Gunnell \& Ben Shlomo, 2000). Exceptions to this "rule" indicate that the association is not automatic, however. For example in the latter $20^{\text {th }}$ century more affluent people were more likely to die in airplane accidents, presumably because they were also more able to afford this relatively expensive form of travel (Davey Smith et al., 2000). Similarly, studies of the British aristocracy suggest that until the $17^{\text {th }}$ or $18^{\text {th }}$ century they appear to have experienced a similar, or even higher, mortality than that of the peasantry (Johansson, 1999). Up to this period particular dietary and hygiene fashions probably increased the risk of British Aristocrats for infectious and some chronic diseases and unhealthy weaning practices contributed to higher infant mortality. Thus there appears to be evidence against a "general susceptibility” explanation for why poorer people tend to have poorer health, rather it seems that specific causes of illness are usually, but not inevitably, associated with material disadvantage. Despite the superficial simplicity of 
the social position/health association more complex questions remain unanswered. These relate to the mechanisms whereby such associations arise and hence to how amenable they are to change through intervention.

\section{Possible pathways between social position and health}

Social health gradients appear to be real, rather than an artefact of social classification systems (Davey Smith, Bartley \& Blane, 1991), moreover social selection, whereby healthier people ascend the social hierarchy, and vice versa, appears to explain a very small proportion of health inequalities, indeed it may lead to reductions in observed inequality (Blane, Harding \& Rosato, 1999). Established physiological risk factors seem an incomplete explanation because they are often not strongly socially patterned (Marmot, 2002). The social distribution of physiological risk is partly a reflection of the social patterning of unhealthy behaviour. Unhealthy diet, lack of exercise and drug use, particularly tobacco use, has only become strongly associated with social disadvantage relatively recently (Tate, 1999). This may explain why, in some studies, consideration of established physiological and behavioural risk factors seems to account for only a relatively small proportion of relative inequality in health between social groups (Davey Smith, Hart, Blane, Gillis \& Hawthorne, 1997) (Marmot, Bosma, Hemingway, Brunner \& Stansfeld, 1997). Similarly, access to health technology appears to be socially patterned and as technology becomes more effective this patterning is likely to contribute to health inequalities (Watt, 2002). However, effective health technology with the ability to substantially influence population health is a relatively recent innovation and, in some cohorts, access to technology does not appear to be as strongly socially patterned as might be expected (Britton, Shipley, Marmot \& Hemingway, 2004). 
The above observations have led some to the conclusion that health inequalities remain substantially unexplained (Marmot, 2002). Others have disputed the magnitude (rather than the existence) of the unexplained proportion and have debated whether attempts to discover new risk factors should take priority over the development of more effective strategies to ameliorate established risk factors (Beaglehole \& Magnus, 2002). It is very likely that the apparent contribution of established behavioural and physiological risk factors to health inequalities has been underestimated because of measurement error (Phillips \& Davey Smith, 1992), particularly with respect to lifetime exposure to established risk factors. Even the more sophisticated studies, typically, measure these factors on a small number of occasions in adulthood and infer lifetime exposure from this. If true exposure across the life course were possible to measure, a different picture would probably emerge.

Against this background, debate over the origin (and hence the way to reduce) health inequalities has, to an extent, polarised around two basic explanatory hypotheses. These have been referred to as the "material" and the "psychosocial" explanations of health inequalities respectively (Lynch, Davey Smith, Kaplan \& House, 2000) (Marmot \& Wilkinson, 2001).

The material hypothesis posits that adverse material conditions are associated with multiple health damaging exposures acting across the life course. These exposures will damage health irrespective of any negative emotions that may be associated with them. The cumulative effect of these factors lead, through multiple specific pathways, to the social patterns of health typically observed in adulthood. Whilst acknowledging 
that negative emotions may foster unhealthy behaviour, the material explanation of health inequalities views such behaviour as more a product of social structures than as a reflection of individual fecklessness. Though individual choice clearly plays some part, the ability of people to make healthy choices is substantially constrained by the contingencies of their lives. A material explanation of health inequalities leads to the expectation that objective social position should show a stronger association with health than subjective status.

Conversely, the psychosocial hypothesis posits that material disadvantage, per se, has little direct influence on health within developed societies. Rather it is the psychological "stress" associated with perceptions of disadvantage that is health damaging. Psychosocial theories see this damage as being realised through both indirect mechanisms, such as an influence on unhealthy behaviour, and direct mechanisms involving neuro-endocrine perturbations and the influence of these on physiological risk (Brunner, 1997) (Brunner, 2002). A psychosocial explanation of health inequalities leads to the expectation that an individual's perception of their relative position on the social hierarchy should show a stronger association with health than objective measures of their social position.

\section{Measuring social position - some considerations}

Historically, social position has been conceptualised in several ways. These include classification systems that are essentially descriptive and those that reflect an underlying model of socio-economic and power relations (Wright, 1987) (Wright, 2000). A distinction between individual perceptions of social position and objective status has long been recognised and the sociological implications of this discussed 
(Vanneman \& Pampel, 1977) (Vanneman, 1980). This discourse has been mirrored by debates amongst epidemiologists regarding different approaches to measuring social position and the consequences of these for investigations of patterns and determinants of population health (Liberatos, Link \& Kelsey, 1988) (Krieger, Williams \& Moss, 1997) (Shaw, Tunstall \& Davey Smith, 2003) (Davey Smith, 2003) (Krieger \& Davey Smith, 2004). Consideration of all the theoretical and ideological arguments around social classification systems is beyond the scope of this paper however two general points are relevant. First, whatever classification system is adopted, social disadvantage is consistently associated with poorer health. Second, it is possible to divide social position measures into those that are essentially objective (that is they are based on a characteristic that is measurable through means independent of individual perceptions) and those that are essentially subjective (that is they reflect individual perceptions of relative status). The first group include measures independently derived from actual occupation, assets and income, area of residence and level of completed education. The second group include measures based on perceptions of individual position on a hierarchy, relative to others. The hierarchy may be represented by a continuous visual analogue scale, from "best off" to "worst off”. Alternatively it may consist of categories of relative status, either in society generally (“working class”, “middle class” etc) or in the workplace ("manager”, "supervisor”, “worker” etc). There is likely to be overlap between these two groups of measures since individuals may base perceptions of their relative status on objective criteria such as their own access to material resources compared to that of others. However there may also be occasions where an individual's perception of their status is discrepant with an objective assessment. Such occasions provide an opportunity to 
test whether subjective, rather than objective, status is the more important determinant of health.

For example, Wright has used the term “contradictory class location” to describe the situation of workers whose hierarchical status is, largely, discrepant with their access to material assets (Wright, 1987) (Wright, 2000). "Status inconsistency” - is a related concept (Vernon \& Buffler, 1988), though rather than an inconsistency between subjective and objective status, this generally refers to inconsistency of status, as measured on any particular scale, at different points of the life course. Wright suggests that the contradictory location is epitomised by the situation of low-level supervisors in the organisational hierarchy who enjoy higher status but little material advantage in relation to their immediate subordinates. If psychosocial (as opposed to material) pathways between social position and health predominate then such workers might be expected to enjoy a health advantage commensurate with their higher status in relation to immediately subordinate workers who experience similar material conditions and rewards.

\section{Objective or subjective status - empirical evidence}

The contemporary debate around the relative importance of objective compared to subjective status arose partly from Richard Wilkinson's work on the association between income distribution and mortality at the ecological level (Wilkinson, 1996). The nature and meaning of this association continues to be vigorously debated (Gravelle, 1998) (Wolfson, Kaplan, Lynch, Ross \& Backlund, 1999) (Wilkinson, 1999) (Lynch et al., 2000) (Marmot \& Wilkinson, 2001) (Lynch, Davey Smith, 
Hillemeier, Shaw, Raghunathan \& Kaplan, 2001) (Mackenbach, 2002) (Lynch, Davey Smith, Harper, Hillemeier, Ross, Kaplan \& Wolfson, 2004).

Individual level evidence of the relative importance of subjective compared to objective status is scarce and mainly cross-sectional. Muntaner and colleagues are one of the few groups to have examined this question (Muntaner, Eaton, Diala, Kessler \& Sorlie, 1998). They compared the relations between social position indicators based on material assets and those based on workplace status with a range of self-reported mental health problems in two large general population surveys. The most striking gradients found were between pure measures of material assets (either income alone or an expanded measure including property, other investments and interest on savings) and health. Prevalence of mood, anxiety and substance abuse disorders increased steadily in relation to increasing material disadvantage. Relations between mental health and status based social position measures were generally weaker and of smaller magnitude. The specific case of individuals in contradictory class locations (as in Wright's scheme) was also considered. Supervisors compared to managers, but also to workers, appeared to be at heightened risk for depression and alcohol abuse. This association was weak, however it could be seen as running counter to the psychosocial hypothesis, which would predict better psychological health amongst supervisors compared to workers - given the higher relative status of the former. Muntaner and colleagues, however, argued that these results could still be seen as supporting a psychosocial mechanism as, despite their superior status, supervisors may experience greater stress due to tensions inherent in their conflicting roles. 
Adler and colleagues studied a small group of women recruited to a laboratory stress study (Adler, Epel, Castellazo \& Ickovics, 2000). Social position was assessed according to objective material assets (income) along with other objective indicators such as education. Subjects also indicated their perceptions of relative social status on a visual analogue scale. Where there was discrepancy between objective and subjective assessments, it appeared that the subjective measure was the better predictor of health. In particular women who perceived their status to be higher had better psychological health and also, if to a lesser degree, favourable scores on some physiological risk measures. The stronger association between perceived status and subjective health suggests that reporting bias may have influenced these findings (Macleod, Davey Smith, Heslop, Metcalfe, Carroll \& Hart, 2002). However the association, albeit weaker, between perceived status and physiological measures could be interpreted as lending support to the psychosocial hypothesis. Others have suggested that psychosocial factors are a particularly important determinant of health in women, compared to men (Denton, Prus \& Walters, 2004).

A similar visual analogue scale was included in a large cross-sectional analysis of a British study of civil servants (Singh-Manoux, Adler \& Marmot, 2003). Lower subjective social status was associated with several dimensions of poorer self-reported health (doctor diagnosis of diabetes, angina symptoms, respiratory symptoms, low mood symptoms and perceived poorer health). Adjustment for markers of objective social status (such as employment grade and income) attenuated these associations such that only the association between lower subjective social status and perceived poorer health remained strong or substantial. The authors concluded that, "subjective social status reflects the cognitive averaging of standard markers of socioeconomic 
situation”. This appears to suggest that subjective status is largely a reflection of objective status and has little, if any, independent effect on health.

\section{The current project}

We attempted to extend these cross-sectional findings and clarify some of these issues using data from a large cohort of working men. We considered various measures of social position including those based on objective material assets and status based measures, in particular those indicative of contradictory class location. We explored the relation between these measures and each other and between social position measures, health related behaviours and other risk factors including perceived psychological stress. We then examined the relation between different social position measures and both morbidity and mortality and how these relations appeared to be mediated through health-related behaviours, physiological risk factors and psychological stress. In particular we addressed the question as to whether individuals in contradictory class locations perceived themselves to be more or less stressed than their immediate subordinates, and whether they enjoyed better or poorer health. 


\section{Methods}

\section{Study Population}

The current investigation is based on a cohort of 5,232 men aged 35-64 years (mean age 48) recruited from 27 workplaces in Scotland between 1970 and 1973. The workplaces were chosen to provide a sample of the occupational spectrum of the male working population. They included engineering, manufacturing and petrochemical plants; a publishing house, civil service departments; administrative and professional divisions from British Rail; legal and dental offices; architectural institutes and banks (Davey Smith, Hart, Hole, MacKinnon, Gillis, Watt et al., 1998). Response rates are available from the workplaces from which $87 \%$ of the sample was recruited. From these sites $70 \%$ of those invited completed a questionnaire and attended a clinical examination. No information is available on non-responders to allow comparison with those screened. Full details of participants and procedures have been published elsewhere (Heslop, Davey Smith, Carroll, Macleod \& Hart, 2001).

\section{Exclusions}

5,425 men recruited at initial screening fulfilled the basic eligibility criteria (age 3564 years, not embarked in the subsequent 25 years, not describing themselves as "selfemployed"). The following variables had missing data, with very few men having information missing on more than one variable: father's social class 105; plasma cholesterol 34; perceived stress 19; current occupation 9; job satisfaction 7; age leaving school 7; postcode of residence 5; Forced expiratory volume in one second \% 4; diastolic blood pressure 3; car access 2; smoking 1; subjective social status 1. 10 men with complete baseline data embarked from the UK in the subsequent 25 years and were therefore lost to follow-up. 


\section{Social position measures}

Occupational class was ascribed based on participant reports of their own current, and their father's main occupation according to the Registrar General's classification (OPCS, 1966). Occupational class was then considered using a manual/non-manual distinction. Whether participants regularly drove a car was measured based on a single question on this. An area-based measure of deprivation was derived from the postcode of participant's normal place of residence according to the system of Carstairs and Morris (Carstairs \& Morris, 1991) (Davey Smith, Hart, Blane, Gillis \& Hawthorne, 1997). Scores were categorised as deprived (scores 6-7), middle (scores 4-5) and affluent (scores 1-3). Participants reported the age at which they left full-time education. Responses were dichotomised at the median into two categories, participants leaving education prior to the age of 15 years and those who left education aged 15 years or older. Height was also taken as a proxy measure of social position given the relatively consistent association between greater adult height and social advantage (Silventoinen, 2003). In addition to being asked to fully describe their actual occupation, participants were asked whether they saw themselves as a “manager”, “foreman” or "employee”, (the small number who described themselves as self-employed were excluded). Foremen were considered to be the equivalent of Wright's workplace supervisor and thus to be occupants of a contradictory class location.

\section{Other measures}

Height, weight, plasma cholesterol and blood pressure were recorded using standard methods (Davey Smith et al, 1998). Forced expiratory volume in one second (FEV1) 
was measured using a Garthur Vitalograph. This value was expressed as a percentage of that predicted from results of a healthy subset of the population who had never smoked and who reported no symptoms of respiratory disease (Davey Smith et al. 1998). Perceived psychosocial stress was measured via the Reeder Stress Inventory (RSI), a four-item instrument measuring global daily stress on a scale of 1 (low stress) to 8 (high stress). Validity and reliability of the RSI in this and other studies has been discussed elsewhere (Metcalfe, Davey Smith, Wadsworth, Sterne, Heslop, Macleod et al., 2003). Participants also reported satisfaction with their job on a five point Likert scale ranging from very dissatisfied to completely satisfied.

Participants reported their use of tobacco (cigarettes smoked daily; ex, current and never smokers). Alcohol consumption in terms of weekly consumption of spirits, beer, and wine was also reported and was converted to units of alcohol by taking one measure of spirits as 1 unit, 1 pint (568ml) of beer as 2 units, and one bottle of wine as 6 units.

\section{Outcome data}

Participants were flagged with the NHS Central Registry, which provides death certificates. Data on hospital admissions for the same period were provided through linkage to the Scottish Morbidity Register (Kendrick \& Clarke, 1993). This has data on all admissions to Scottish hospitals. Admissions to general hospitals (SMR1) and to psychiatric hospitals (SMR4) were considered. Codes appearing in any diagnostic position (up to six are allowed) from the final consultant episode were used as these were presumed to represent the most definitive diagnoses for that admission. Deaths were coded according to the $9^{\text {th }}$ revision of the International Classification of Diseases 
(ICD). Admissions were coded according to the contemporaneous revision of the ICD. Cardiovascular diseases were encompassed by ICD (revisions 8-9) codes 390459 and ICD10 codes I20-I25; psychiatric disorders by ICD8 codes 291, 295-300 and 303-307; ICD9 codes 291, 292, 295-298, 300, 303-309, 311, 312 and 316 and ICD10 codes F10-F51 F54 F55 F63 (sexual deviation, personality disorder and developmental problems were excluded). Lung cancer was encompassed by ICD9 code 162; peptic ulcer by ICD8 and 9 codes 531-534 and ICD10 codes K25-K28; accidents and violence by ICD9 codes 800-995 and alcohol related causes by ICD8 and 9 codes 291, 303 and 571 and ICD10 codes F10, K70 and K74. Mortality data and hospital admission data were censored at 25 years from date of first screening.

\section{Stastistical analysis}

Survival and hospital free survival were compared between groups using proportional hazards models. For each fully adjusted hazard ratio presented the veracity of the proportional hazards assumption was investigated using Schoenfeld's test (Schoenfeld, 1980). In no case was evidence against the proportional hazards assumption obtained. Age was included as the time scale in all models with time at risk taken to start at date of screening. Social position measures, smoking and alcohol consumption and perceived stress were added sequentially to models.

All analyses were undertaken using the software package STATA 8.0. (Stata Corporation, 2003). 


\section{Results}

In general, disadvantageous social position was associated with an unfavourable profile of disease risk factors whatever the measure of social position used (Table 1). The exceptions to this rule were plasma cholesterol, perceived stress, and job satisfaction where advantageous social position was associated with an adverse risk profile. 906 men described themselves as “managers”, 459 as “foremen” and 3867 as “employees” Foremen reported higher stress than employees and only slightly lower stress than managers (age adjusted t-test for difference in mean stress between foremen and employees $\mathrm{p}<0.001$, between foremen and managers $\mathrm{p}=0.12$ ). With regard to most other risk factors, foremen and employees were very similar. A greater proportion of foremen (than either managers or employees) were heavy smokers.

The data in table 2 support the assertion that foremen occupy a contradictory class location. Despite their higher status, foremen were more similar to employees than to managers in terms of most other measures of social position. They were similarly likely to hold a manual occupation, to have a father with a mainly manual occupation, to live in a deprived area and to have left school before the age of 15 years. Mean height of foremen was intermediary between that of managers and employees. Foremen were also more likely than employees to have access to a car. As can be seen in table 1, managers, foremen and employees had a very similar mean age. Age standardisation made no substantial difference to proportions in table 2.

Table 3 shows that in this population, poorer health potential (as indexed by all cause mortality) is associated with social disadvantage whatever the measure of social position used. This relation does not appear to be completely mediated via established 
behavioural or physiological risk factors though adjustment for these led to attenuation of most estimates. Additional adjustment for psychological stress had little influence. Father's occupational class, car access and height appear to show the strongest association with mortality with excess risk associated with disadvantage still being strongly apparent after adjustment for other social position measures. Workplace status, current occupational class and educational attainment are only weakly associated with poorer health after adjustment for other social position measures. Area of residence has essentially no association with poorer health after adjustment for other social position measures.

Table 4 shows that with regard to most classes of morbidity and mortality the health experience of foremen is little different to that of employees but substantially different to that of managers. Both employees and foremen generally experienced worse health than managers. Foreman, as opposed to employee, status was weakly protective in relation to all cause mortality, lung cancer death, deaths through accidents or violence, peptic ulcer and alcohol-related problems. A slightly stronger protective effect was apparent in relation to psychiatric illness. In contrast, manager status was strongly protective in relation to most of these outcomes. Foremen had a weakly increased risk of cardiovascular disease compared to both managers and employees. Adjustment for current occupational class caused the greatest attenuation of these associations with adjustment for other social position measures causing further attenuation. Adjustment for smoking and alcohol consumption, perceived stress and job satisfaction had little additional effect. Death from lung cancer showed a slight departure from this pattern. Employees had a weakly increased risk of lung cancer compared to foremen. A 
weakly protective effect amongst managers (compared to foremen) was reversed on adjustment for other social position measures.

There were no differences in morbidity or mortality between men with complete baseline data $(\mathrm{n}=5232)$ and those with missing data $(\mathrm{n}=192)$ other than that a higher proportion of men with missing data subsequently experienced an admission to psychiatric hospital (4.9\% cf. 8.9\%, chi-squared for difference $\mathrm{p}=0.015$ ) or an alcohol related illness ( $2.5 \% \mathrm{cf}$. $4.7 \%$, chi-squared for difference $\mathrm{p}=0.052$ ). 


\section{Discussion}

Health and social position

Social disadvantage was associated with poorer health (as indexed by all cause mortality) in this population, whatever the measure of social position used. Having a father in a manual occupation was the strongest predictor of poorer health. Other strong predictors were height and car access. Workplace status, current occupation, educational status and area of residence were all strongly associated with health in age-adjusted analyses. Adjustment for health behaviours and physiological risk factors attenuated these associations. Adjustment for psychological stress had little influence. Workplace status, current occupation, educational status and area of residence showed little association with health after adjustment for other measures of social position.

\section{Objective compared to subjective social position}

Men in contradictory class locations, that is men who enjoyed higher workplace status but who were similar to their subordinates in terms of other social position measures, had, in general, a similar health experience to these subordinates. Their status advantage did not appear to confer any substantial health advantage. Foremen, compared to employees, experienced a reduced risk of most of the categories of morbidity and mortality in table 4. However, the evidence in support of these estimated differences did not provide any strong basis to discount the null hypothesis of no difference between the two groups of men. In terms of cardiovascular disease (the most important cause of health inequality within this population) there was actually a suggestion that foremen were at higher risk than employees. 
The role of psychological stress

Within the psychosocial explanatory framework, the predicted health of individuals in contradictory class locations depends on the psychological impact that such a location is assumed to have on the individual occupying it. Muntaner and colleagues suggest that this impact will be negative (Muntaner et al., 1998). In their study a weak relation between "supervisor" status and increased prevalence of substance misuse disorders appeared to support this suggestion. Our data provide some further support for this conceptualisation. Foremen reported higher psychological stress than employees (though not managers) and were more likely than both employees and managers to be heavy smokers in cross-sectional analyses at recruitment (proportions of current smokers were almost identical between employees and foremen).

An alternative conceptualisation, as suggested by the work of Wilkinson, is that the superior relative status of foremen should have a positive psychological impact and that this should further translate into better health (Wilkinson, 1999). This framework appears to be supported by the findings of Adler and colleagues who found a closer relation between higher subjective (as opposed to objective) social status and better self-reported physical and psychological health (Adler et al., 2000). More recently, Mustard and colleagues also found that occupational prestige was directly associated with perceived health status, particularly in men (Mustard, Vermeulen \& Lavis, 2003). Objective measures of health status were not available in this study and it is likely that reporting tendency influenced the associations found between prestige and perceived health (Macleod et al. 2002). The association was attenuated following adjustment for psychosocial work characteristics but apparently not by adjustment for household income (data on the latter were not shown). 
In the present study, foremen had a reduced risk of admission to hospital with a psychiatric disorder compared to employees. However it is difficult to attribute this to a positive psychological impact of their workplace status as foremen reported higher stress than employees.

These data cast further doubt on the importance of psychological stress as an important cause of social gradients in physical disease (Macleod, Davey Smith, Heslop, Metcalfe, Carroll \& Hart, 2001). Managers, the group reporting highest stress, had a substantially lower risk of admission to hospital for peptic ulcer - the condition that for much of the follow-up period of this study would have been considered the classic “stress disease” (Susser \& Stein, 2002). Managers may have been more mobile than foremen or employees (75\% of managers, compared to $69 \%$ of foremen and $42 \%$ of employees, regularly drove a car). Conceivably, this may have made them more likely to be admitted to hospital outside of Scotland. Such admissions would not have been recorded (death outside of Scotland is recorded) however it seems unlikely that the protective effect of managerial status is substantially attributable to bias of this nature. Managers also had a considerably lower experience of other health outcomes related to psychological distress such as deaths from accidents and violence, alcohol related morbidity and mortality and psychiatric hospitalisation. Adjustment for social position measures considerably attenuated all these relations. Adjustment for smoking and alcohol consumption (which in the cohort as a whole were strongly associated with stress) (Heslop et al., 2001) and for stress made little difference to estimates. 
Issues related to measurement of social position and related factors

One aim of the present study was to examine the relative contribution of subjective, compared to objective, social status to health. In this regard we faced the same difficulty that every investigation of this question has encountered. There is no pure “subjective” measure of social status. Workplace titles or positions on visual analogue scales are both likely to be attributed by individuals at least partly on the basis of objective criteria. One criterion will almost certainly relate to differences in access to material assets. In most organisations, foremen are likely to be better remunerated than employees, however marginally. This may explain why foremen were more likely to have access to a car.

Employee status was not an “independent” predictor of greater mortality amongst the disadvantaged in this cohort. This could be interpreted as suggesting that employee status was merely another indicator of social position, since it had no apparent influence on health after estimates were adjusted for other social position measures. Such an interpretation could be seen as running counter to the psychosocial hypothesis. Inferior relative perceived status was not associated with poorer health. Some caution is warranted in relation to this interpretation. First, we had mixed evidence as to whether negative feelings were, in fact, related to inferior status in this cohort. Higher status was associated with higher perceived stress. However psychological problems, alcohol related problems and accidents and violence could all be taken as evidence of poorer mental health and employees experienced greater risk of all of these outcomes. Indeed it would be surprising if perceptions of ones own lower access to material assets and life choices were not associated with any negative feelings on the part of the person experiencing this disadvantage. 
But height, car access and father’s occupational class were (unlike workplace status) independently associated with mortality. Whilst it is possible that particular negative feelings may be associated with short stature, or the necessity of using public transport, or may be forged during a working class childhood, (Harper, Lynch, Hsu, Everson, Hillemeier, Raghunathan, Salonen et al., 2002) other considerations seem more likely explanations of the apparently independent effect of these measures on health. All social position indicators are likely to be proxies for the true exposure of interest (the cumulative effect of socially patterned health damaging and health protecting factors acting across the life course), but different indicators will relate more strongly to particular aspects of such life course exposure. The apparently independent associations with health of these indicators may reflect this. For example, height and father's occupational class may index exposures related to childhood social environment, and car access during a particular historical period may index an additional dimension of access to material resources. Independent effects of a particular indicator do not necessarily suggest a particular mechanism - material or psychosocial - involving that indicator. Further, residual independent effects of certain factors may simply reflect measurement imprecision of correlated covariates (Phillips \& Davey Smith, 1991) (Phillips \& Davey Smith, 1992). A similarly independent effect of job control in the Whitehall II study was taken by others to suggest that job control had a key explanatory role in relation to social inequalities in health (Marmot et al., 1997). We have suggested that this interpretation should be treated cautiously for the reasons discussed above (Davey Smith \& Harding, 1997). 


\section{Strengths and limitations of the present study}

An advantage of our study was the availability of relatively objective outcome measures such as hospital admission and mortality. Individual perceptions of social status appear strongly associated with individual perceptions of health, but these relations may substantially reflect reporting bias (Ostrove, Adler, Kuppermann \& Washington, 2000) (Macleod et al., 2002). Hospital admission data may be a less biased measure of morbidity. However most morbidity, particularly psychological morbidity, is unlikely to lead to hospital admission. The social patterning of the morbidity that does not lead to hospital admission may be different from that which does.

It has been suggested that psychological factors may have a particular role in relation to health inequalities amongst women (Denton et al. 2004). We were unable to investigate this question as our study only included men.

Behavioural factors such as diet and exercise may influence health and we did not include measures of these in our analysis. To an extent, variations in diet and exercise may be reflected in variations in BMI, which we did include. Nevertheless, we may have underestimated an influence of diet and exercise in this study population.

Our measure of perceived global stress might be criticised by some though similar measures are still used in contemporary studies (Rosengren, Hawken, Ounpuu, Sliwa, Zubaid, Almahmeed, Blackett, Sitthi-amorn, Sato \& Yusuf, 2004). The measure is distinct from the workplace specific construct of "job strain” (the coincidence of high job demands with low job control) originally advanced by Karasek and Theorell 
(Karasek and Theorell, 1990). Measures of "psychosocial adversity” typically show a high degree of covariance and we have argued the validity of this measure in relation to more recent and elaborate instruments elsewhere (Metcalfe et al., 2003). The social patterning of perceived stress in this population (stress was not higher amongst the socially disadvantaged by any measure of social position), arguably, made an important role for psychological mechanisms of disease aetiology unlikely. Our global stress measure has shown high concurrent validity with results of other instruments measuring the same construct so that it is seems unlikely that use of an alternative instrument would have markedly changed the apparent social patterning of global stress (Metcalfe et al., 2003). More narrowly defined psychological constructs such as hostility, and social constructs such as job control appear consistently related to social disadvantage and there appears no reason to suppose the patterning of these constructs would have been any different in this population (Hemingway \& Marmot, 1999). These constructs would thus have appeared associated with health, however such associations do not necessarily suggest a particular causal mechanism. For example, in this cohort higher stress was associated with lower risk of death from smoking related cancers, despite an association between higher stress and heavier smoking (Macleod et al., 2001). This association between stress and cancer risk probably arose because higher stress was also associated with social advantage. Caution is warranted when attributing causality to any relation between a socially patterned exposure and a health outcome.

We only had one measure of social position that primarily reflected perceived status rather than access to material assets. This measure of relative status was specific to the workplace and may not have reflected wider perceptions of relative status, such as 
may be measured by other instruments. However it had the advantage of relating to a particular theory of social class and use of it allowed us to compare our results with those from other investigations that had used a similar theoretical framework (Muntaner et al., 1998). Moreover, psychosocial theorists have claimed a particular importance for workplace related exposures (Hemingway \& Marmot, 1999).

Comparison of our findings on the psychological morbidity of individuals occupying contradictory class locations with those of previous studies was constrained by our use of different measures of psychological morbidity. Arguably, our data on admission to hospital was a "harder" endpoint than the self-reported symptoms used in the study by Muntaner and colleagues. However use of this endpoint meant we had fewer events and consequently less power. Though men occupying contradictory class locations did not experience higher risk of psychiatric admission than their immediate subordinates they did report higher stress. In the cohort as a whole, higher stress was strongly and substantially related to higher risk of psychiatric admission (Macleod et al., 2002).

Participation in baseline screening was $70 \%$ amongst those invited. If participants differed substantially from non-participants with respect to the factors studied then this might have biased our findings. Similarly, if the Scottish population we studied was in some way substantially atypical compared to other populations this too might limit external validity. The relation between social position and health, and between established behavioural and physiological risk factors and health was the same in this population as that typically seen elsewhere, (Davey Smith et al. 1997) (Macleod et al., 2002) casting doubt on the suggestion that this population was atypical. One, perhaps 
unusual, characteristic of this population was the association between higher perceived stress and social advantage that provided the opportunity to investigate any independent effect of stress on health inequalities.

\section{Implications}

Our findings suggest several conclusions. They confirm the existence of social inequalities in health and demonstrate that such inequalities exist whether subjective or objective social classifications are used. They illustrate that different indicators of social position may capture different dimensions of disadvantage experienced across the life course and the health consequences of this. They also confirm that although unhealthy behaviours are commoner amongst socially disadvantaged people, such behaviours appear to explain only part of the social health gradient in cohorts of this age. They lend no support to the suggestion that psychosocial stress, associated with perceptions of relative social status is an important determinant of health. Furthermore they suggest that associations between perceived social status and objective health arise predominantly because most individuals appear objectively accurate in their assessment of their own relative social status.

Our findings give little support to the thesis that subjective social status is a more important determinant of health than objective social status. Rather they suggest that even in a relatively economically advanced society - it is material inequality itself, rather than any psychosocial correlate of such inequality that is the key determinant of health inequalities. 


\section{Acknowledgements}

The work of Victor Hawthorne, Charles Gillis, David Hole and Pauline MacKinnon has provided us with the data required for this analysis. A grant within phase two of the Economic and Social Research Council's, Health Variations research programme allowed linkage to hospital admission data. JM is supported by a Career Scientist fellowship from the Department of Health. All views expressed are those of the authors and not necessarily of the Department of Health. 
Table 1. Relation between alternative indices of social position, behavioural, physiological and psychosocial risk factors (adjusted for age)

\begin{tabular}{|c|c|c|c|c|c|c|c|c|c|c|c|}
\hline & $\mathrm{n}$ & $\begin{array}{c}\text { Mean } \\
\text { age } \\
\text { (years) }\end{array}$ & $\begin{array}{l}\text { \% } \\
\text { current } \\
\text { smokers }\end{array}$ & $\begin{array}{l}\text { \% heavy } \\
\text { smokers } \\
\text { (>24 } \\
\text { cigarettes } \\
\text { daily) }\end{array}$ & $\begin{array}{l}\% \\
\text { heavy } \\
\text { drinkers } \\
(>15 \\
\text { units } \\
\text { weekly) }\end{array}$ & $\begin{array}{l}\text { Mean } \\
\text { diastolic } \\
\text { blood } \\
\text { pressure } \\
\text { (mmHg) }\end{array}$ & $\begin{array}{l}\text { Mean } \\
\text { plasma } \\
\text { cholesterol } \\
(\mathrm{mmol} / \mathrm{l})\end{array}$ & $\begin{array}{l}\text { Mean } \\
\text { Body } \\
\text { Mass } \\
\text { Index } \\
\left(\mathrm{kgm}^{-2}\right)\end{array}$ & $\begin{array}{l}\text { FEV1 } \\
\% \\
\text { predicted }\end{array}$ & $\begin{array}{l}\text { Mean } \\
\text { perceived } \\
\text { stress }\end{array}$ & $\begin{array}{l}\% \\
\text { completely } \\
\text { satisfied } \\
\text { with their } \\
\text { job }\end{array}$ \\
\hline \multicolumn{12}{|l|}{$\begin{array}{l}\text { Current } \\
\text { occupation }\end{array}$} \\
\hline $\begin{array}{l}\text { Manual } \\
\text { Non- }\end{array}$ & 2751 & 48.7 & 63.1 & 15.2 & 40.1 & 84.7 & 5.65 & 25.2 & 90.4 & 3.48 & 16.3 \\
\hline manual & 2481 & 47.8 & 48.1 & 11.8 & 17.4 & 83.1 & 6.06 & 25.1 & 97.8 & 4.03 & 9.1 \\
\hline \multicolumn{12}{|l|}{$\begin{array}{l}\text { Father's } \\
\text { occupation }\end{array}$} \\
\hline $\begin{array}{l}\text { Manual } \\
\text { Non- }\end{array}$ & 4130 & 48.3 & 58.0 & 14.0 & 32.5 & 84.2 & 5.80 & 25.3 & 92.8 & 3.67 & 13.9 \\
\hline manual & 1102 & 48.0 & 48.6 & 11.9 & 17.5 & 83.0 & 6.02 & 24.9 & 98.0 & 4.00 & 9.1 \\
\hline \multicolumn{12}{|l|}{$\begin{array}{l}\text { Area of } \\
\text { residence }\end{array}$} \\
\hline Deprived & 1576 & 49.0 & 63.9 & 17.1 & 41.0 & 84.1 & 5.72 & 25.0 & 90.5 & 3.60 & 14.7 \\
\hline Middle & 1985 & 48.3 & 56.2 & 12.3 & 27.0 & 84.3 & 5.82 & 25.4 & 94.0 & 3.70 & 13.0 \\
\hline Affluent & 1671 & 47.4 & 48.2 & 11.8 & 21.2 & 83.3 & 5.98 & 25.1 & 97.0 & 3.91 & 11.0 \\
\hline \multicolumn{12}{|l|}{ Car-access } \\
\hline No & 2613 & 49.1 & 62.0 & 14.1 & 38.1 & 84.0 & 5.77 & 25.0 & 91.7 & 3.62 & 13.7 \\
\hline Yes & 2619 & 47.4 & 50.0 & 13.0 & 20.7 & 83.8 & 5.92 & 25.4 & 96.1 & 3.86 & 12.1 \\
\hline \multicolumn{12}{|l|}{$\begin{array}{l}\text { Age on } \\
\text { leaving } \\
\text { full-time } \\
\text { education }\end{array}$} \\
\hline$<15$ years & 2834 & 49.6 & 60.9 & 14.2 & 37.7 & 84.3 & 5.74 & 25.3 & 91.2 & 3.55 & 16.2 \\
\hline $15+$ years & 2398 & 46.6 & 50.1 & 12.7 & 19.6 & 83.5 & 5.97 & 25.1 & 97.1 & 3.96 & 8.9 \\
\hline \multicolumn{12}{|l|}{ Height } \\
\hline $\begin{array}{l}\text { Median or } \\
\text { less }\end{array}$ & 3044 & 48.9 & 58.0 & 13.5 & 33.2 & 83.7 & 5.80 & 25.3 & 93.9 & 3.70 & 13.7 \\
\hline > Median & 2188 & 47.3 & 53.2 & 13.6 & 24.0 & 84.2 & 5.90 & 25.0 & 93.9 & 3.80 & 11.7 \\
\hline \multicolumn{12}{|l|}{$\begin{array}{l}\text { Workplace } \\
\text { status }\end{array}$} \\
\hline Employee & 3867 & 48.3 & 59.1 & 13.3 & 31.1 & 84.0 & 5.78 & 25.1 & 92.4 & 3.49 & 13.9 \\
\hline Foreman & 459 & 48.1 & 57.3 & 18.2 & 28.0 & 84.9 & 5.80 & 25.5 & 94.8 & 4.37 & 9.3 \\
\hline Manager & 906 & 48.0 & 42.1 & 12.1 & 18.0 & 83.1 & 6.14 & 25.2 & 99.8 & 4.48 & 10.2 \\
\hline
\end{tabular}


Table 2. Relation between workplace status and other measures of social position (adjusted for age)

\begin{tabular}{|c|c|c|c|c|c|}
\hline & Workplac & status & & & \\
\hline & $\begin{array}{l}\text { Manager } \\
(n=906)\end{array}$ & $\begin{array}{l}\text { Foreman } \\
(n=459)\end{array}$ & $\begin{array}{l}\text { Employee } \\
(\mathrm{n}=3867)\end{array}$ & $\begin{array}{l}\mathrm{p} \text { for } \\
\text { trend }\end{array}$ & $\begin{array}{l}\text { Number in } \\
\text { category }\end{array}$ \\
\hline $\begin{array}{l}\text { Proportion regularly driving a } \\
\text { car } \%\end{array}$ & 74.8 & 69.0 & 42.0 & $<0.001$ & 2619 \\
\hline Proportion residing in a deprived & & & & & \\
\hline area \% & 8.9 & 28.1 & 35.2 & $<0.001$ & 1576 \\
\hline $\begin{array}{l}\text { Proportion residing in an affluent } \\
\text { area \% }\end{array}$ & 58.8 & 30.7 & 25.6 & $<0.001$ & 1671 \\
\hline $\begin{array}{l}\text { Proportion whose father was in a } \\
\text { non-manual social class } \%\end{array}$ & 42.2 & 14.4 & 16.9 & $<0.001$ & 1102 \\
\hline $\begin{array}{l}\text { Proportion in a non-manual } \\
\text { occupational class \% }\end{array}$ & 98.6 & 35.4 & 36.8 & $<0.001$ & 2481 \\
\hline $\begin{array}{l}\text { Proportion who left full-time } \\
\text { education aged } 15+\text { years } \%\end{array}$ & 78.3 & 41.6 & 38.3 & $<0.001$ & 2398 \\
\hline Mean height cm & 175.8 & 173.4 & 171.8 & $<0.001$ & \\
\hline
\end{tabular}

Wilcoxon-type test for trend; obtained using Stata’s nptrend command (Cuzick, 1985) 
Table 3. Relative risks of all cause mortality (2158 deaths) over 25 years of follow-up according to different measures of social position

\begin{tabular}{|c|c|c|c|c|c|c|}
\hline & $\begin{array}{l}\text { Number } \\
\text { of } \\
\text { deaths }\end{array}$ & Adjusted for age & $\begin{array}{l}\text { Adjusted for age } \\
\text { and behavioural } \\
\text { risk factors }^{1}\end{array}$ & $\begin{array}{l}\text { Adjusted for age } \\
\text { and all risk } \\
\text { factors }^{2}\end{array}$ & $\begin{array}{l}\text { Adjusted for age, } \\
\text { risk factors, } \\
\text { stress and job } \\
\text { satisfaction }\end{array}$ & $\begin{array}{l}\text { Adjusted for age, risk } \\
\text { factors, stress, job } \\
\text { satisfaction and other social } \\
\text { position measures }\end{array}$ \\
\hline \multicolumn{7}{|c|}{ Current occupation } \\
\hline Non-manual & 874 & 1.00 & 1.00 & 1.00 & 1.00 & 1.00 \\
\hline \multicolumn{7}{|c|}{ Father's occupation } \\
\hline Non-manual & 368 & 1.00 & 1.00 & 1.00 & 1.00 & 1.00 \\
\hline Manual & 1790 & $1.41(1.26,1.58)$ & $1.30(1.17,1.46)$ & $1.26(1.12,1.41)$ & $1.25(1.11,1.40)$ & $1.16(1.03,1.31)$ \\
\hline \multicolumn{7}{|c|}{ Area of residence } \\
\hline Deprived & 748 & $1.35(1.21,1.50)$ & $1.17(1.05,1.31)$ & $1.15(1.03,1.29)$ & $1.15(1.03,1.28)$ & $1.02(0.91,1.15)$ \\
\hline \multicolumn{7}{|l|}{ Car-access } \\
\hline Yes & 923 & 1.00 & 1.00 & 1.00 & 1.00 & 1.00 \\
\hline no & 1235 & $1.32(1.21,1.44)$ & $1.20(1.10,1.31)$ & $1.17(1.07,1.29)$ & $1.17(1.07,1.28)$ & $1.12(1.02,1.23)$ \\
\hline \multicolumn{7}{|c|}{$\begin{array}{l}\text { Age on leaving full-time } \\
\text { education }\end{array}$} \\
\hline $15+$ years & 799 & 1.00 & 1.00 & 1.00 & 1.00 & 1.00 \\
\hline$<15$ years & 1359 & $1.32(1.21,1.44)$ & $1.21(1.11,1.32)$ & $1.17(1.07,1.29)$ & $1.16(1.06,1.27)$ & $1.05(0.95,1.17)$ \\
\hline
\end{tabular}




\title{
Height
}

\section{$-10 \mathrm{~cm}$}

$1.17(1.11,1.25)$

$1.14(1.07,1.21) \quad 1.15(1.08,1.22)$

$1.15(1.08,1.22)$

$1.09(1.02,1.16)$

Workplace status

Manager 288

Foreman

288

\begin{abstract}
$0.75(0.62,0.90)$
\end{abstract}
$0.82(0.68,0.99)$

$0.84(0.69,1.01)$

$0.84(0.69,1.01)$

$0.91(0.74,1.10)$

Employee

1.00

1.00

1.00

1.00

1.00

${ }^{1}$ Cigarette smoking and alcohol consumption

${ }^{2}$ Cigarette smoking, alcohol consumption, plasma cholesterol, BMI, $\mathrm{FEV}_{1}$, diastolic blood pressure 
Table 4. Cause specific mortality and morbidity over 25 years of follow up associated with different levels of workplace status

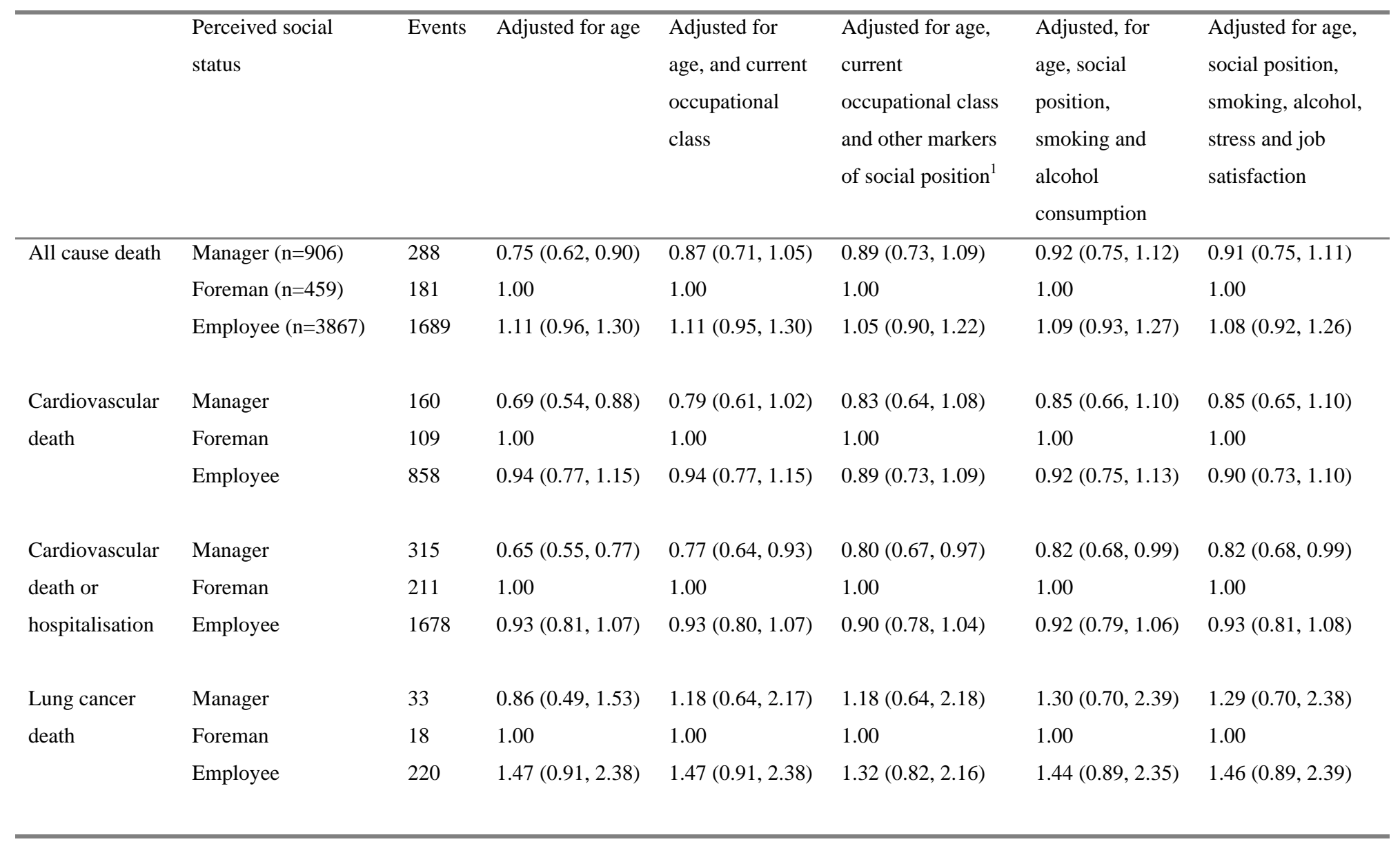




\begin{tabular}{|c|c|c|c|c|c|c|c|}
\hline Death through & Manager & 4 & $0.38(0.10,1.41)$ & $0.50(0.13,1.97)$ & $0.52(0.13,2.05)$ & $0.51(0.13,2.02)$ & $0.51(0.13,2.03)$ \\
\hline accident or & Foreman & 5 & 1.00 & 1.00 & 1.00 & 1.00 & 1.00 \\
\hline violence & Employee & 55 & $1.32(0.53,3.30)$ & $1.32(0.53,3.30)$ & $1.19(0.47,3.01)$ & $1.18(0.47,3.00)$ & $1.15(0.45,2.94)$ \\
\hline Death or & Manager & 19 & $0.37(0.20,0.67)$ & $0.45(0.24,0.84)$ & $0.45(0.24,0.85)$ & $0.46(0.24,0.86)$ & $0.46(0.24,0.86)$ \\
\hline hospitalisation & Foreman & 24 & 1.00 & 1.00 & 1.00 & 1.00 & 1.00 \\
\hline Death or & Manager & 12 & $0.64(0.27,1.51)$ & $0.92(0.37,2.31)$ & $0.99(0.39,2.47)$ & $0.91(0.36,2.30)$ & $0.90(0.36,2.27)$ \\
\hline hospitalisation & Foreman & 9 & 1.00 & 1.00 & 1.00 & 1.00 & 1.00 \\
\hline $\begin{array}{l}\text { with alcohol- } \\
\text { related causes }\end{array}$ & Employee & 107 & $1.43(0.73,2.83)$ & $1.44(0.73,2.84)$ & $1.02(0.51,2.03)$ & $1.05(0.53,2.10)$ & $1.18(0.59,2.38)$ \\
\hline hospitalisation & Foreman & 15 & 1.00 & 1.00 & 1.00 & 1.00 & 1.00 \\
\hline & Employee & 217 & $1.75(1.04,2.95)$ & $1.75(1.04,2.95)$ & $1.50(0.88,2.54)$ & $1.52(0.89,2.57)$ & $1.70(1.00,2.90)$ \\
\hline
\end{tabular}

${ }^{1}$ father's occupational class, area of residence, car access, age at leaving full-time education, height. 


\section{References}

Adler NE, Epel ES, Castellazo G, \& Ickovics JR. (2000) Relationship of subjective and objective social status with psychological and physiological functioning: preliminary data in healthy white women. Health Psychology, 19 (6), 586-592.

Beaglehole R, Magnus P. (2002) The search for new risk factors for coronary heart disease: occupational therapy for epidemiologists? International Journal of Epidemiology, 31(6), 1117-22.

Black D, Morris JN, Smith C, \& Townsend P., (1980) Inequalities in health: report of a research working group. London: Department of Health and Social Security.

Blane D, Harding S, \& Rosato M., (1999) Does social mobility affect the size of the socio-economic mortality differential? Evidence from the ONS longitudinal study. Journal of the Royal Statistical Society [Series A] 162 (Pt 1), 59-70.

Britton A, Shipley M, Marmot M, Hemingway H. (2004) Does access to cardiac investigation and treatment contribute to social and ethnic differences in coronary heart disease? Whitehall II prospective cohort study. BMJ, 329(7461), 318-321.

Brunner E. (1997) Stress and the biology of inequality. BMJ, 314 (7092),1472-6.

Brunner E., (2002) Stress mechanisms in coronary heart disease. In Stansfeld SA, \& Marmot MG (eds). Stress and the heart: psychosocial pathways to coronary heart disease. (pp.181-199). London: BMJ Books.

Carstairs V, \& Morris R., (1991) Deprivation and health in Scotland. Aberdeen: Aberdeen University Press.

Chadwick E., (1965) Report of the sanitary conditions of the labouring population of Great Britain, 1842. Edinburgh: Edinburgh University Press.

Cuzick J. (1985) A Wilcoxon-type test for trend. Statistics in Medicine, 4 (1), 87-90. 
Davey Smith G, Bartley M, \& Blane D, (1991) Black on class and health: a reply to Strong. Journal of Public Health Medicine, 13 (4), 350-9.

Davey Smith G., (1997) Socioeconomic differentials. In Kuh D, \& Ben-Shlomo Y (eds). A life course approach to chronic disease epidemiology. (pp.242-273). Oxford: OUP.

Davey Smith G, Carroll D, Rankin S, \& Rowan D. (1992) Socioeconomic differentials in mortality: evidence from Glasgow graveyards. BMJ, 305 (6868),15541555.

Davey Smith G, \& Harding S. (1997) Is control at work the key to socio-economic gradients in mortality? Lancet, 350 (9088), 1369-70.

Davey Smith G, Gunnell D, \& Ben-Shlomo Y. (2000) Life-course approaches to socio-economic differentials in cause-specific adult mortality. In: Leon D, \& Walt G. (eds.) Poverty, Inequality and Health. (pp.88-124). Oxford: Oxford University Press. Davey Smith G, Hart C, Blane D, Gillis C, \& Hawthorne V. (1997) Lifetime socioeconomic position and mortality: prospective observational study. BMJ, 314 (7080), 547-52.

Davey Smith G, Hart C, Hole D, MacKinnon P, Gillis C, Watt G, Blane D, \& Hawthorne V. (1998) Education or social class: which is the more important indicator of mortality risk? Journal of Epidemiology and Community Health, 52 (3), 153-160. Davey Smith G (ed.) (2003) Health inequalities: life course approaches. Bristol: Policy Press.

Denton M, Prus S, Walters V (2004) Gender differences in health: a Canadian study of the psychosocial, structural and behavioural determinants of health. Social Science and Medicine, 58 (12), 2585-2600. 
Engels F. (1987) The condition of the working class in England. (1 ${ }^{\text {st }}$ edition 1845). Harmondsworth: Penguin.

Gravelle H. (1998) How much of the relation between population mortality and unequal distribution of income is a statistical artefact? BMJ, 316 (7128), 382-385.

Harper S, Lynch J, Hsu WL, Everson SA, Hillemeier MM, Raghunathan TE, Salonen JT \& Kaplan GA. (2002) Life course socioeconomic conditions and adult psychosocial functioning. International Journal of Epidemiology, 31 (2), 395-403.

Hart JT. (1972) Data on occupational mortality, 1959-63: too little and too late. Lancet, I (7743), 87-90.

Hemingway H, \& Marmot M. (1999) Evidence based cardiology: Psychosocial factors in the aetiology and prognosis of coronary heart disease: systematic review of prospective cohort studies BMJ, 318 (7196), 1460-1467.

Heslop P, Davey Smith G, Carroll D, Macleod J, Hyland F \& Hart C. (2001) Perceived stress and coronary heart disease risk-factors: The contribution of socioeconomic position. British Journal of Health Psychology 6, 167-178.

Johansson SR. (1999) Death and the doctors: medicine and elite mortality in Britain from 1500 to 1800. Cambridge: Cambridge Group for the History of Population and Social Structure Working Paper Series number 7.

Karasek R, \& Theorell T. (1990) Healthy work: stress, productivity and the reconstruction of working life. New York: Basic Books, 1990.

Kendrick S, \& Clarke J. (1993) The Scottish record linkage system. Health Bulletin $51(2), 72-79$.

Krieger N, Williams DR, \& Moss NE. (1997) Measuring social class in US public health research. Annual Review of Public Health 18, 341-78. 
Krieger N, Davey Smith G. (2004) "Bodies count," and body counts: social epidemiology and embodying inequality. Epidemiologic Reviews, 26, 92-103.

Liberatos P, Link BG, \& Kelsey JL. (1988) The measurement of social class in epidemiology. Epidemiologic Reviews 10, 87-121.

Logan WPD. (1954) Social class variations in mortality. British Journal of Preventive and Social Medicine ;8,128-37.

Lynch JW, Davey Smith G, Kaplan GA et al. (2000) Income inequality and mortality: importance to health of individual income, psychosocial environment, or material conditions BMJ 320 (7243), 1200-1204.

Lynch J, Davey Smith G, Hillemeier M, Shaw M, Raghunathan T, Kaplan G. (2001) Income inequality, the psychosocial environment, and health: comparisons of wealthy nations. Lancet, 358(9277), 194-200.

Lynch J, Davey Smith G, Harper S, Hillemeier M, Ross N, Kaplan GA, Wolfson M. (2004) Is income inequality a determinant of population health? Part 1. A systematic review. Milbank Quarterly. 82(2), 5-99.

Macleod J, Davey Smith G, Heslop P, Metcalfe C, Carroll D, \& Hart C. (2001) Are the effects of psychosocial exposures attributable to confounding? Evidence from a prospective observational study on psychological stress and mortality. Journal of Epidemiology and Community Health. 55 (12), 878-84.

Macleod J, Davey Smith G, Heslop P, Metcalfe C, Carroll D, \& Hart C. (2002) Psychological stress and cardiovascular disease: empirical demonstration of bias in a prospective observational study of Scottish men. BMJ 324 (7348), 1247-51.

Mackenbach JP. (2002) Income inequality and population health. BMJ 324 (7328), 12. 
Marmot MG. Bosma H. Hemingway H, Brunner E \& Stansfeld S. (1997) Contribution of job control and other risk factors to social variations in coronary heart disease incidence. Lancet. 350 (9073), 235-9.

Marmot M, \& Wilkinson RG. (2001) Psychosocial and material pathways in the relation between income and health: a response to Lynch et al BMJ 322 (7296), 12331236.

Marmot M. (2002) Commentary: occupational therapy or the major challenge? International Journal of Epidemiology, 31(6), 1122-24.

Metcalfe C, Davey Smith G, Wadsworth E, Sterne JAC, Heslop P, Macleod J, \& Smith A. (2003) A Contemporary validation of the Reeder Stress Inventory. British Journal of Health Psychology 8, 83-94.

Muntaner C, Eaton WW, Diala C, Kessler RC, \& Sorlie PD. (1998) Social class, assets, organizational control and the prevalence of common groups of psychiatric disorders. Social Science and Medicine 47 (12), 2043-53.

Mustard CA, Vermeulen M, Lavis JN. (2003) Is position in the occupational hierarchy a determinant of decline in perceived health status? Social Science and Medicine 57 (12), 2291-2303.

OPCS. (1966) Classification of Occupations 1966. London: HMSO.

Ostrove JM, Adler NE, Kuppermann M, \& Washington AE. (2000) Objective and subjective assessments of socioeconomic status and their relationship to self-rated health in an ethnically diverse sample of pregnant women. Health Psychology. 19 (6), 613-8.

Phillips AN, \& Davey Smith G. (1991) How independent are independent effects? Relative risk estimation when correlated exposures are measured imprecisely. Journal of Clinical Epidemiology 44 (11), 1223-31. 
Phillips AN, \& Davey Smith G. (1992) Bias in relative odds estimation owing to imprecise measurement of correlated exposures. Statistics in Medicine 11 (7), 953961.

Rosengren A, Hawken S, Ounpuu S, Sliwa K, Zubaid M, Almahmeed WA, Blackett KN, Sitthi-amorn C, Sato H \& Yusuf S. (2004) Association of psychosocial risk factors with risk of acute myocardial infarction in 11119 cases and 13648 controls from 52 countries (the INTERHEART study): case-control study. Lancet 364 (9438), 953-962.

Schoenfeld D. (1980) Chi-squared goodness-of-fit tests for the proportional hazards regression model. Biometrika, 67, 145-53.

Shaw M, Tunstall, H , \& Davey Smith, G. (2003) Seeing social position: visualizing class in life and death International Journal of Epidemiology 32 (3), 332-335.

Silventoinen K. (2003) Determinants of variation in adult body height. Journal of Biosocial Science. 35 (2), 263-85.

Singh-Manoux A, Adler, N.E, \& Marmot, M.G. (2003) Subjective social status: its determinants and its association with measures of ill-health in the Whitehall II study. Social Science and Medicine, 56 (6), 1321-1333.

Stata Corporation. (2003) Stata statistical software: release 8.0. College Station Houston TX: Stata Corp.

Stevenson THC. (1923) The social distribution of mortality from different causes in England and Wales 1910-12. Biometrika 15, 382-400.

Susser M, Stein Z. (2002) Commentary, civilisation and peptic ulcer 40 years on. International Journal of Epidemiology 31 (1), 18-21.

Tate C. (1999) Cigarette wars: the triumph of "the little white slaver". Oxford: OUP. 
Vanneman R, Pampel FC. (1977) The American perception of class and status. American Sociological Review 42, 422-437.

Vanneman RD. (1980) US and British perceptions of class. American Journal of Sociology 85, 769-790.

Vernon SW \& Buffler PA. (1988) The status of status inconsistency. Epidemiologic Reviews 10, 65-86.

Watt G. (2002) The inverse care law today. Lancet 360 (9328), 252-54.

Wilkinson RG. (1996) Unhealthy Societies. London: Routledge.

Wilkinson RG Health, heirarchy and social anxiety. (1999) In Adler NE, Marmot M, McEwen B, \& Stewart J (eds.) Annals of the New York Academy of Sciences: vol. 896. Socioeconomic status and health in industrial nations: Social, psychological and biological pathways (pp. 48-63). New York: New York Academy of Sciences.

Wolfson M, Kaplan G, Lynch J, Ross N, \& Backlund E. (1999) Relation between income inequality and health: empirical demonstration. BMJ 319 (7215), 953-955.

Wright E,O. (1987) Class boundaries and contradictory class locations. In Giddens A, \& Held D. (Eds.) Classes power and conflict. (pp.112-129). London: Macmillan. Wright EO. (2000) Class Counts. Cambridge: Cambridge University Press. 